\title{
NARRATIVAS DE CORPOS DOCENTES NO ENCONTRO COM O UNIVERSO INFANTIL
}

\author{
Ana Lúcia Rodrigues da Silva ${ }^{\mathrm{i}}$ \\ Mariana Alonso López-López ${ }^{\text {ii }}$ \\ Raianne da Silva Alves Bernardo Thomaz iii
}

\begin{abstract}
Resumo: Um corpo que se move diz sobre o que sente. Esta pesquisa quer mostrar a importância de se estar atento aos corpos das crianças, para sermos capazes de construir de forma coletiva uma relação positiva ou bom encontro. Estar aberto para perceber o que diz o corpo de uma criança ao se mover e entender que ela também é capaz de sentir o que o nosso corpo adulto expressa, traz para a consciência o fato de que os corpos dialogam de acordo com a simbologia de seus movimentos. Estar em uma relação de aprendizagem de corpo inteiro é acreditar que a qualidade dos vínculos que criamos com as crianças hoje, será a base dos vínculos que elas criarão no futuro.
\end{abstract}

Palavras-chave: Corpo; Criança; Relação; Vínculo; Brincar.

\section{NARRATIVAS DE LOS CUERPOS DOCENTES EN EL ENCUENTRO CON EL UNIVERSO INFANTIL}

Resumen: Un cuerpo em movimento dice lo que siente. Esta investigación quiere mostrar la importancia de estar atento al cuerpo de los niños para sermos capaces de construir colectivamente una relación positiva o un buen encuentro. Estar abierto a percibir lo que dice el cuerpo de un niño cuando se mueve y comprender que él también es capaz de sentir lo que expresa nuestro cuerpo adulto, hace que se tome conciencia de que los cuerpos dialogan según el simbolismo de sus movimientos. Estar en una relación de aprendizaje de cuerpo entero es creer que la calidad de los vínculos que creamos con los niños hoy, será la base de los vínculos que crearán en el futuro.

Palabras-clave: Cuerpo; Niño, Relación, Vínculo; Jugar.

\section{Introdução}

O presente artigo é fruto do encontro entre três professoras-psicomotricistas que decidiram olhar de forma sensível e atenta para as relações corporais no ambiente escolar. Iniciamos esse texto contando um pouco das nossas histórias que se entrelaçam com a prática que desenvolvemos nas instituições que trabalhamos. Nossas experiências como educadoras se revelam e se potencializam no encontro com as crianças. Como pesquisadoras, pensamos a infância na perspectiva de experiências vividas de corpo inteiro em qualquer tempo e lugar. 
Temos como objetivo dar visibilidade ao corpo, aos encontros e mostrar a importância do processo de formação de vínculo nas instituições e entre os seres. Para isso, trazemos temas que dissertam sobre a disponibilidade dos corpos adultos para encontrar as crianças e se permitir caminhar junto com elas, mergulhando de corpo e alma nesse universo pequenino por fora, e grande por dentro.

Nossa principal proposta é acompanhar a criança em sua descoberta respeitando sua singularidade e liberdade expressiva. O diálogo com diferentes autores dos campos da Educação e Filosofia, nos permitiu teorizar nossas práticas nas escolas e o resultado de nossa interlocução com estes estudiosos estão descritos no decorrer dessas páginas.

Iniciamos chamando a atenção para um corpo que fala, afeta e se deixa afetar. Um corpo que precisa do olhar sensível e da escuta atenta, necessitando de espaço e tempo para se movimentar e comunicar em liberdade. A seguir, trazemos a beleza da potência dos bons encontros entre educadores e crianças, quando estes estão em sintonia com a imprevisível e espontânea natureza humana. Escrevemos também sobre a construção do vínculo, que perpassa pela escuta do corpo e pelos encontros, para que possa ser tecido em um tempo próprio no dia a dia.

E, para finalizar, narramos três situações vivenciadas em nossa prática com as crianças. Acreditamos na importância de ilustrar o texto com as experiências reais, para trazer vida a uma escrita reflexiva. É acompanhando os passos das crianças que encontramos a maneira mais justa e afetiva de construir caminhos ao longo do ano. Os gestos das crianças nos dão pistas de por onde ir. Só precisamos estar atentos para observá-los.

\section{Apresentações}

Como professoras e psicomotricistas percebemos a importância de escrever sobre a educação psicomotora que defendemos e vivenciamos em nossas práticas como docentes. Ao pensar nessa área do conhecimento, a primeira palavra que pensamos e sentimos é vida. Sem ela não existe a união entre o corpo e a mente e não existe o sujeito que se movimenta. Foi na psicomotricidade também que compreendemos o quanto os corpos podem nos falar sobre suas necessidades, desejos, alegrias, curiosidades e potência no encontro com outros seres. 


\section{Educadora I:}

Sou alimentada pelos sonhos e a vida me ensinou a costurar pedras e entrelaçar fios. Com três dias de nascida, fui adotada por uma família que me deu todo o amor do mundo e que hoje transborda nos laços e abraços que dou e recebo. Como mulher e irmã mais velha, comecei a lutar por um lugar no mundo desde muito cedo.

Passei minha infância e adolescência numa fazenda no interior do Ceará, chamada Boágua. Lá não havia energia elétrica, tudo era muito natural e o tempo de ócio garantia a liberdade de sentir. Perto da nossa casa tinha um açude grande com muitos peixes, onde eu me divertia nadando de um lado para o outro, pulando das pedras para mergulhar. No quintal dos meus avós, diariamente, eu entrava em contato com a natureza onde criava meus próprios brinquedos, utilizando os elementos que encontrava no chão.

Hoje, percebo que, ali, o brinquedo começava desde o momento que eu catava os gravetos e juntava as folhas caídas no chão. Piorski (2016), em seu livro Brinquedos de chão, fala sobre a importância do uso desses materiais que ganham novos sentidos de acordo com a necessidade e a criatividade das crianças. "A criança deposita no mundo pequenos fragmentos encantatórios, os mitos que provêm do imaginário" (PIORSKI, 2016, p. 135). No quintal, eu encontrava vários fragmentos entre pedras, gravetos, cascas de árvores e galhos. Descobri minha criatividade e capacidade inventiva de explorar, que transcendia energia no meio de tanta riqueza e afeto que existiam nesses materiais.

Nessa época, o tempo de brincadeira era sagrado e a simplicidade vivida na infância foi me constituindo como pessoa. Nesse lugar, era possível perceber os sinais da natureza no contato com a terra, no banho de açude, no passeio de bicicleta e no cheiro de terra molhada quando chovia.

O vento trazia a lua tão próxima, que clareava as noites escuras, deixando ainda mais vivas as histórias que meu avô contava. O silêncio, que era uma característica da fazenda, propiciava a escuta desses elementos, e a energia do planeta tornava esses momentos tão mágicos, que estão guardados até hoje na minha memória.

Meu lugar de estudo eram as árvores, onde eu subia com meus cadernos e não via o tempo passar, aproveitando para saborear a seriguela que pegava nos galhos. $\mathrm{Eu}$, assim como Manoel de Barros, cresci brincando no chão.

Cresci brincando no chão, entre formigas. De uma infância livre e sem comparamentos. Eu tinha mais comunhão com as coisas do que comparação. 
Porque se a gente fala a partir de ser criança, a gente faz comunhão: de um orvalho e sua aranha, de uma tarde e suas garças, de um pássaro e sua árvore.

(BARROS, 2010, p. 187)

Atuo como educadora na Educação Infantil desde 2000 e, durante a minha trajetória, venho pesquisando temáticas relacionadas à infância, corpo e movimento, considerando o corpo como um canal de comunicação, de afetos e aprendizagens. Por trabalhar com crianças tão pequenas, muitas que ainda se comunicam por meio do corpo, precisei buscar temáticas que dialogassem com a minha atuação, pois só a formação como Pedagoga não deu conta das minhas inquietações.

\section{Educadora II:}

Colocaram etiquetas no meu corpo desde que nasci. Uma no meu pequeno braço de bebê branco e outra social. Meu rosto se parece com o do meu pai, mas sinto em mim muitas coisas da minha mãe também. Sou a mistura dos dois, mais as experiências que vivi dando meus próprios passos. Minhas partes foram se acomodando aos poucos, mas eu não paro de chegar com novidades. Me sinto em crescimento, sempre.

Vivo, sinto e logo percebo uma parte que se expandiu, outra que encolheu e uma outra que amadureceu. Nem sempre sei de cara onde acomodar o que chega. Tem horas que tudo fica bagunçado mesmo, mas no compasso do vento e das ondas do mar, meus lugares de calmaria, o espaço se abre e chega o tempo do que era novo sentir que já me pertence.

Sou também educadora física, psicomotricista educacional e mestranda em educação. Mas essas são só outras etiquetas. O que gosto mesmo é de ver meu corpo sentir o mundo e partilhar da vida junto a outros corpos que encontro no caminho. Entre bons e maus encontros eu continuo me surpreendendo com os desenhos que sou capaz de fazer de mim. As crianças me ajudam muito a me ver. São parte importante desse processo de me perder e me achar e o mais importante de tudo é que me ajudam a não esquecer da criança que fui.

Então sou essa, antes menina, agora mulher, que a partir de seus encontros se parte, se reparte e se integra, para conhecer seu novo inteiro. Fico um tempo olhando, mas a impermanência logo começa outro ciclo de partir, repartir e reintegrar... E lá estou eu redesenhada pelas vivências desse corpo que sente e trata de se (re)conhecer a cada fase de uma vida que passa mais rápido do que eu gostaria. 


\section{Educadora III:}

Eu sou mulher, professora, pesquisadora e psicomotricista. Filha, neta, sobrinha, esposa e, em breve, serei mãe. Nascida em Magé, Rio de Janeiro, moradora convicta da Baixada Fluminense, prezo pelo espaço e pelas pessoas com as quais convivo. Como profissional, me vejo na interlocução das características mencionadas. Sou corpo, natureza e, às vezes, criança, me constituindo a cada dia nos encontros da vida. Acredito na potência das relações e na importância dos afetos.

Professora, com as crianças me permito sensibilizar o olhar e a escuta para um corpo potente e presente, que dialoga com o meu a cada acontecimento na escola. Juntos conhecemos o mundo e eu me reencontro com minha criança interior, permitindo-me a alegria da docência em buscar, conhecer e aprender com elas.

Como professora, busco diálogos de aprendizagem; como pesquisadora, fundamento a minha prática e construo minha docência na práxis; e como psicomotricista, percebo as crianças como seres corporais, sujeitos da natureza, que se constituem nos encontros com os outros e com o mundo.

\section{A poesia dos encontros corporais na escola}

Palavras, frases oralizadas e textos, são consideradas formas de comunicação entre os seres humanos. Mas antes de escrever, ler ou falar, iniciamos nossa comunicação no mundo através da linguagem corporal.

Bebês e suas famílias se comunicam por expressões e gestos, e para toda a vida nossas caretas, rostos emburrados, sorrisos, cabeça baixa, corpo ereto, contam sobre quem somos e como estamos. "[...] o corpo contém e produz aquilo que somos [...], se expressa e apresenta a partir e através das diferentes manifestações do movimento" (FRANCH e MASTRASCUSA, 2016, p. 31). Nos encontros com as diferentes formas de vida, nossos corpos falam entre si, em um diálogo corporal.

Nosso corpo conta histórias da vida que vivemos até aqui. Calos nas mãos, arranhões na pele, joelhos marcados pelos tombos... Cicatrizes produzidas em momentos em que estamos aprendendo a dar nossos próprios passos e a sermos responsáveis por nós mesmos. 
Quanta potência tem o corpo que nos fala! Porém, nos vemos constantemente desafiados a viver entre a liberdade corporal para se expressar e o silenciamento imposto aos corpos dentro dos espaços educativos.

$\mathrm{Na}$ escola, costumam não ver e ouvir o que de dentro se expressa nessa extensão corporal. A instituição aprisiona o corpo do ser criança para que apenas a mente funcione. Como uma faca que corta o pão em duas partes, eles separam o corpo da cabeça, sem perceber que não há vida sem a unidade corpo e mente (FOCAULT, 1987). Porém, não vamos aqui nos deter ao aprisionamento e sim, refletir sobre livre expressão corporal e narrar histórias sobre corpos que conversam entre si, se compreendem e se potencializam nos encontros, nas relações e na vida.

Segundo Franch e Mastrascusa (2016) "a comunicação não-verbal, inseparável de nossas ações, envolve as relações humanas dando a elas uma ou outra tonalidade afetiva e carregando-as de significação" (p. 37). O corpo, em movimento e em relação, traz a possibilidade de comunicações afetivas e potentes. A escola pode se abrir para encontros significativos de aprendizagens reais que ocorrem na vida e no contato com o mundo. É preciso ver e ouvir o corpo que nos fala e, muitas vezes, gritam pelo olhar do outro.

Para haver diálogo é preciso atenção e interação. Desta forma "a emoção nutre-se do efeito que causa no outro, isto é, as reações que as emoções suscitam no ambiente funcionam como uma espécie de combustível para sua manifestação" (GALVÃO, 2015, p. 64). O choro e o sorriso são manifestações corporais, formas de se comunicar com os outros seres e para que ela exerça seu papel, há a necessidade de reação do interlocutor pela mensagem emitida pelo locutor a partir de suas ações.

É importante que os professores compreendam que "expressar-se significa exteriorizarse, colocar-se em confronto com o outro, organizar-se" (GALVÃO, 2014, p. 99). Ao se expressar, exteriorizar e colocar para fora, a criança ou o professor se comunica, mesmo que não emita sons, pois o corpo fala e necessita que alguém o acolha.

Na psicomotricidade chamamos à conversa entre os corpos de diálogo tônico, ele põe em jogo "a inter-relação de dois sujeitos, e a relação entre duas pessoas não é nunca unidirecional. Permanentemente se dá uma emissão de mensagens em ambos os sentidos que configuram esse processo" (FRANCH e MASTRASCUSA, 2016, p. 65). O outro que recebe a mensagem, ao negá-la, anula o emissor, e ao respondê-la o potencializa. 
Por meio do diálogo tônico as crianças muito pequenas compreendem o dito e o não dito, pois a linguagem não se restringe à fala, mas envolve as ações corporais, o olhar e a modulação da voz.

Segundo Wallon (2007) é essencial que o diálogo tônico entre a criança e o adulto que cuida dela seja sublime, pois, as marcas (negativas e positivas) são indeléveis e vão influenciar no modo de agir desta criança.

Outra forma de chamar esse diálogo é de linguagem não-verbal, e é importante sinalizar a partir de Franch e Mastrascusa (2016), que ele não se diferencia da linguagem verbal ao explicitar que as duas são produzidas pelo corpo. O que as difere são as formas: emissão de sons ou gestos, encontro de olhares entre outras inúmeras possibilidades que o corpo humano tem para se manifestar.

A Transpsicomotricidade Educacional (TrPmEd) reuniu a transdisciplinaridade e o pensamento complexo às linhas livres expressivas da psicomotricidade, a fim de valorizar o livre brincar como ferramenta principal no desenvolvimento pleno do sujeito. Colocamos nosso olhar e corpo disponíveis para as necessidades corporais e construções subjetivas de cada criança, acreditando que através de interações positivas, o sujeito construirá sua identidade e autonomia plena de forma mais segura.

O Transpsicomotricista concebe a criança na sua inteireza, em todas as suas dimensões: psíquica, física, biológica, social, cultural, histórica e acredita que toda comunidade escolar deve se envolver em prol do desenvolvimento do pequeno. Os encontros transpsicomotores permitem a criança se revelar e, segundo Costa (2017):

Possibilitam à criança poder mergulhar nos seus sentimentos e emoções (aflições, medos e alegrias). Vai se apropriando dos saberes, enriquecendo seu repertório cognitivo, afetivo, social, cultural, motor e ético. Por meio de novos esquemas de ação, dá significado às suas vivências, socializando-se, percebendo o próprio ritmo e o do outro, enfrentando situações e resolvendo problemas. (p. 67)

Nas vivências TransPsicomotoras as crianças encontram um espaço de livre expressão para brincar, criar e aprender sobre si na relação com o outro, com o espaço e com os objetos. O adulto que as acompanha, desempenha um papel de suporte às demandas que surgem e ocupa um lugar de parceiro simbólico nos jogos que ela cria, favorecendo que a criança se sinta confiante em viver toda sua potência e fragilidades em um lugar seguro e preparado para ela.

Através dos princípios TransPsicomotores procuramos trabalhar valores como empatia, ética e respeito à diversidade, pautados no Pensamento Complexo e Transdisciplinar, Revista Interinstitucional Artes de Educar. Rio de Janeiro, V. 7, N. 1 - pág. 132-150 janeiroabril de 2021: "Pedagogias Vitais: Corpo, Desejo e Educação" DOI: 10.12957/riae.2021.54496 
beneficiando assim o sujeito de forma completa para que viva uma vida livre, solidária e feliz. O Pensamento Complexo "é capaz de contextualizar e globalizar, mas pode ao mesmo tempo reconhecer o que é singular e concreto" (MORIN, 2007, p. 76). Em suas obras, Morin busca salientar a importância da união dos saberes e do construir-se em relação ao próprio contexto de estar no mundo, percebendo que o todo é maior que a soma das partes.

Como professoras-psicomotricistas, entendemos que diariamente precisamos estar atentas às manifestações corporais de nossas crianças, validando-as como importantes para o processo de construção do conhecimento. Compreendemos em nossas experiências profissionais que necessitamos nos colocar no lugar de interlocutor do diálogo tônico, aquele que se abre para entender os anseios das crianças com inteireza e conduzir os próximos passos para os encontros futuros.

\section{Os encontros}

Se afetamos e somos afetados por tudo que nos acontece, podemos dizer que somos constituídos pelas experiências que vivemos. As que registramos como boas, nos potencializam e nos expandem em direção a um crescimento saudável em alegria. Já as experiências que registramos como más, se não forem trabalhadas para que as feridas sejam cicatrizadas e para que as vejamos como parte de um crescimento difícil, podem acabar nos adoecendo ou criando barreiras para o nosso processo de desenvolvimento.

Se nos afetamos de forma positiva temos um bom encontro. Um bom encontro é capaz de nos potencializar e tornar o caminho de desenvolvimento e autoconhecimento muito mais prazeroso e com boas lembranças.

Uma educação que abre espaço para que nossos desejos naturais possam ser em paz e que nos encoraja a enfrentar nossas dificuldades, humaniza e cuida de um ser em constante formação.

Se agimos de acordo com a nossa natureza, sabemos que a "essência (de um ser) não pode ser concebida sem a sua existência" (ESPINOSA, 1983, p. 9). Portanto, abrir espaço para que bons encontros possam acontecer é também permitir que cada ser em sua singularidade possa existir em um espaço que é de todos.

Para ver acontecer bons encontros dentro das instituições de Educação Infantil é preciso promover experiências que sensibilizem o olhar docente: 
Sensíveis porque são processos permeados pelas informações que nos chegam não somente pela via do intelecto, mas também a partir do corpo, pelas vias sensoriais e perceptivas, que muitas vezes são deixadas de lado nas aprendizagens escolares (de adultos e de crianças). (FERREIRA, GUEDES e LAGE, 2019, p. 21)

Se os professores se perceberem como seres sensíveis, entendendo que precisam estar inteiros em suas experiências com as crianças, terão olhares mais amplos e menos hierárquicos para as vivências que podem ter junto a elas.

Um corpo adulto disponível para o imprevisto do corpo da criança, acolhe infâncias que se expressam a partir de seus desejos e da forma como enxergam o mundo. E essa visão da criança, que conta sobre ela, não pode ser ignorada:

O "mundo do faz de conta" faz parte da construção pela criança da sua visão do mundo e da atribuição do significado às coisas. No entanto, esta expressão "faz de conta" é algo inapropriada para referenciar o modo específico como as crianças transpõem o real imediato e o reconstroem criativamente pelo imaginário, seja importando situações e personagens fantasistas para o seu quotidiano, seja interpretando de modo fantasista os eventos e situações que ocorrem. (SARMENTO, 2002, p. 16)

Ignorar a criança em sua espontaneidade é invisibilizar uma infância acontecendo bem diante de olhos adultos, endurecidos demais para saírem do centro de si mesmos e abrirem-se ao que a criança lhes traz. Os maus encontros se desenham neste cenário de opressão, hierarquia e imposição do poder adulto sobre a ingenuidade infantil.

[...] é preciso viver com as crianças, experiências ampliadas e diversificadas com o corpo, que proporcionem o reconhecimento e compreensão de suas sensações, de sua intimidade e afetividade nas relações com os adultos e com seus pares, por meio de massagens, banhos coletivos de mangueira, toques de carinho, em momentos de sentir a respiração, o pulsar e as batidas do coração, os paladares, os perfumes e odores, os sons e ruídos do corpo e da natureza[...] (BUSS-SIMÃO, 2019, p. 65-66)

Experiências boas e ruins fazem parte da vida. Não há como controlar a forma como as coisas vão acontecer, por isso precisamos estar abertos ao inesperado. Com o tempo, a ideia é que a gente vá aprendendo a desfrutar do que nos acontece de bom e a reagir com um olhar mais compassivo ao que nos acontece de ruim, sem vitimismo, aceitando tudo como parte de nosso processo de amadurecimento entre amor e dor. Afinal, "uma experiência vivida é uma transição" (TRINDADE, 2014).

Revista Interinstitucional Artes de Educar. Rio de Janeiro, V. 7, N. 1 - pág. 132-150 janeiroabril de 2021: "Pedagogias Vitais: Corpo, Desejo e Educação" DOI: 10.12957/riae.2021.54496 
Ao fim, todos os nossos movimentos são na direção da preservação da vida. Lutamos para poder existir em paz e caber em um mundo nem sempre compreensivo e tolerante às diferenças. Não sabemos como seremos afetados, nem como reagiremos aos sentimentos advindos das experiências do corpo. Porém, se ao menos sabemos o que queremos e o que não queremos para nós, o rumo de nossa vida pode ser mais na direção a bons que maus encontros.

Tiriba (2005) diz que "não há pontos de chegada, não há portos seguros onde ancorar definitivamente, esta é uma condição da própria existência. Mas há sentidos, há desejos que definem escolhas, trajetos [...]" (p. 151).

A vida é uma jornada de autoconhecimento na qual podemos mergulhar profunda ou superficialmente. O fato é que quanto mais nos conhecemos, maiores são as chances de que nossas decisões nos permitam existir diante de nós mesmos. Ter coragem para existir, aceitando quem somos é uma das coisas mais importante que podemos ensinar às nossas crianças.

Aprender pelo afeto é criar espaços de acolhimento dentro de espaços destinados a transmitir conhecimentos. Na psicomotricidade acredita-se que os afetos se localizam no tônus, que não existe movimento que não esteja ligado ao afeto e que em nosso corpo estão todas as marcas de prazer e de dor de nossas vivências.

Sabemos que o corpo é o primeiro instrumento de exploração e conhecimento do ser humano sobre o mundo, expressado de formas variadas, pelos sons, gestos, tonicidade, suas necessidades afetivas, físicas e cognitivas. (BATISTA, LAPIERRE e VIEIRA, 2005, p. 44)

Nossa saúde tem a ver com a saúde de nossos relacionamentos e conscientes disso, tentar promover bons encontros durante as experiências que dividimos com as crianças é um desafio e uma responsabilidade, pois nesses encontros deixamos marcas. A expressão de um corpo nos conta sobre prazeres e dores. Exposto, o tecido corporal se relaciona com o mundo externo e vai ganhando as marcas de suas experiências. Um corpo não se expressa só a partir de movimentos, mas também das emoções guardadas nesta pele, que divide o que vive dentro e fora de nós. Ferraro (2018) afirma a força dessas expressões corporais:

As emoções são como as impressões. Instantâneas, quase os fotogramas daquilo que se dá anteriormente. Uma foto. Uma imagem. E nós estamos expostos às emoções que são velozes, incisivas, breves. Estamos cercados delas, e é uma linguagem de comunicação eficaz e direta. (p. 187) 
Uma experiência positiva nem sempre é aquela que promove sentimentos prazerosos. Pode também ser aquela onde diante do acolhimento do desconforto, a criança pode experimentar sensações de desprazer, mas sentir-se em um espaço seguro que vai cuidar do que ela sentir e aceitá-la como ela é, com suas potências e fragilidades. Por isso é importante observar as reações das crianças às propostas e aos ambientes que exploram e entram em contato, perguntar o que ela está sentindo e acolher a resposta sem julgamentos ou frustrações.

Só uma pedagogia que respeite as vontades do corpo poderá manter viva a potência infantil, pois o livre movimento dos corpos está na sua origem, e possibilita o encantamento, o questionamento, a indagação e o conhecimento das crianças em relação ao mundo físico e social, ao tempo e à natureza. (TIRIBA, 2010, p. 5)

Ainda que como adultos tenhamos expectativas, ser capaz de acolher o que surge no imprevisto de um momento é essencial para criar um ambiente onde a criança se sinta segura para se expressar em sintonia com a sua natureza, que é espontânea, inocente e verdadeira.

É importante que a criança aprenda a encontrar um caminho para verbalizar o que sente sem medo de ser repreendida. Escutar o sentir da criança, antes de sobrepor o nosso saber adulto com uma ordem, é educar com afeto. Crescer em um ambiente afetivo, contribui para que a criança desenvolva meios de construir relações afetivas saudáveis com mais naturalidade e menos dificuldade.

\section{A construção do vínculo}

Campos (2003) nos diz que vínculo é um vocábulo de origem latina, algo que ata ou liga pessoas. O vínculo é uma conexão. Ele só é possível quando estabelecemos uma relação de confiança e para que isso aconteça precisamos estar inteiros na relação e dispostos a escutar o outro: o que ele pensa, sente, deseja. Ouvir de corpo inteiro!

Nesse sentido, um sujeito que é escutado em suas necessidades, desenvolve a segurança afetiva para poder se expressar com competência sobre si mesmo, sendo capaz de buscar respostas para suas próprias perguntas.

O equilíbrio emocional é um ponto muito importante e desafiador nos dias atuais, pois a criança percebe o campo energético. A criança pode perceber quando nosso corpo está agitado e mesmo quando não colocamos em palavras, nosso tônus muscular comunica. É preciso criar 
algumas estratégias, pois cada criança exige um olhar, onde a singularidade deve ser respeitada e compreendida.

Segundo Soares (2017, p. 22) "o tempo dedicado aos cuidados representa o melhor momento para um encontro privilegiado quando o vínculo afetivo pode ser construído e aprofundado." É nesse contato mais íntimo e individual que a criança se sente segura para viver suas potências e fragilidades. Sentindo-se nutrida pelo afeto, ela segue brincando no coletivo, sabendo que tem um adulto com quem pode contar e que confia nas suas potências.

Colocar-se em sintonia com o outro é o ponto crucial onde a conexão acontece numa troca verdadeira, onde a criança percebe que você está ali para receber e compreender suas emoções, sentimentos, frustrações, o que vier. As crianças precisam saber que confiamos nelas e que elas têm espaço de autoria na construção da sua história.

Escuta envolve cuidado e respeito ao ritmo de cada um, e isso é fundamental para o desenvolvimento integral da criança. Estabelecer uma relação segura e calorosa, promove uma sintonia afetiva entre o pequeno e o adulto e, consequentemente, o vínculo é formado.

É preciso que a empatia, a confiança e inteireza permeiem as relações. Estar comprometido com o outro na construção de um vínculo em que o corpo seja reconhecido plenamente e não reduzido a seu aspecto cognitivo é necessário para o desenvolvimento pleno da criança.

É comum que no início do ano as crianças estranhem o espaço escolar e a mudança de professores, devido ao tempo em que ficaram em casa com a família nas férias. É por isso que necessitam de um acolhimento para estabelecer vínculos afetivos. Algumas precisam de mais tempo para sentir-se seguras e para que o adulto não seja mais um estranho para ela. O corpo e o colo nesse período são fundamentais para a criação desses laços: "a comunicação não-verbal, inseparável de nossas ações, envolve as relações humanas dando a elas uma ou outra tonalidade afetiva e carregando-as de significação" (FRANCH e MASTRASCUSA, 2016, p. $37)$.

Todos os aprendizados passam pelo corpo. Por isso escutar as crianças significa perceber o que seu corpo comunica por meio do olhar, dos gestos, movimentos, sons, linguagem, a relação com o outro (adultos e crianças), etc. Com isso, a experiência sensível aguça os sentidos em contato com o mundo ao seu redor.

Uma criança quando está bem, ela brinca! Quando a criança percebe que o adulto está inteiro na relação, a construção do vínculo acontece naturalmente por meio do brincar. Assim, a disponibilidade do olhar do adulto para as ações das crianças é fundamental para o Revista Interinstitucional Artes de Educar. Rio de Janeiro, V. 7, N. 1 - pág. 132-150 janeiroabril de 2021: "Pedagogias Vitais: Corpo, Desejo e Educação" DOI: 10.12957/riae.2021.54496 
desenvolvimento de propostas que dialogam com seus desejos e necessidades. Pensar o lugar do corpo nos espaços educacionais implica em garantir propostas, espaços e liberdade de ser. Muitas vezes ela só precisa ser olhada e acompanhada, sabendo que pode contar com um adulto que respeita o seu livre expressar no brincar autônomo.

É através da brincadeira que a criança recria, interpreta e estabelece relações com o mundo em que vive. Nesse sentido, o brincar de faz de conta não é, portanto, uma atividade ausente de regras, porém, estas são criadas e partilhadas pelos próprios participantes.

Brincar é atentar para o presente. Uma criança que brinca está envolvida no que faz enquanto o faz. Se brinca de médico, é médico; se brinca de montar num cavalo, é isso que ela faz. O brincar não tem nada a ver com o futuro. Brincar não é uma preparação para nada, é fazer o que se faz em total aceitação, sem considerações que neguem sua legitimidade. (MATURANA e VERDEN-ZÖLLER, 1993, p. 230)

O brincar abre para as crianças muitas janelas para o campo simbólico e para a compreensão da realidade. São inúmeras as possibilidades quando se é permitido às crianças que sejam autoras, criem e aprendam a olhar e compreender o mundo por outros ângulos. É nessa liberdade que elas reinventam suas próprias histórias, que são compartilhadas com os parceiros de brincadeiras, construindo vínculos e novas regras. Segundo Friedmann (2004):

Todas as linguagens lúdicas, as crianças, sem consciência, falam de si, das suas realidades, do que estão vivendo, de como estão vendo o mundo; revelam suas angústias, alegrias, medos e potenciais; revelam seus interesses, o que sabem e precisam. (p. 132)

Brincar cumpre, portanto, uma função primordial porque permite à criança soltar a imaginação, ou seja, criar situações lúdicas a partir dos acontecimentos, pois brincando ela expressa seus pensamentos, suas emoções e sentimentos. No brincar as crianças vão, também, se constituindo como agentes de suas experiências sociais, organizando com autonomia suas ações e interações.

\section{Narrativas dos nossos encontros com as crianças}

Nesta seção narramos três encontros que vivenciamos com as crianças nas escolas. 
Narrativa I:

Trago aqui a experiência de uma vivência durante a Colônia de Férias que coordeno. Nesse dia disponibilizei alguns tecidos de cores e texturas variadas, cuja finalidade era favorecer a interação das crianças com o material oferecido, dando a ele diferentes significados.

Os tecidos representam, analogicamente, tudo o que pode envolver. Sendo assim, logo se transformam em cabanas, capas, vestidos, camas, travesseiros etc. Permitem também, pelo disfarce, a identificação com personagens imaginários ou reais. Todas as propostas oferecidas ao grupo, colocaram o corpo da educadora transpsicomotricista disponível e aberto às relações com as crianças. Elas iam ao seu encontro para interagir e convidá-la a participar das brincadeiras. Ao final das atividades, temos um momento para que as crianças se expressem através do suporte gráfico, revelando as emoções e sentimentos do corpo vivido.

Uma menina de cinco anos, enquanto desenhava, disse à transpsicomotricista: "Vou te dizer o que mais gostei: deitar na sua barriga". Com isso percebemos que, para além do material oferecido, o que está em jogo sempre é a relação. A disponibilidade do adulto não invade o espaço da criança, mas espera o seu movimento de busca, estando aberto a acolhê-la quando a demanda surgir.

Tomando como exemplo a fala da menina de cinco anos, entramos em sintonia com a psicomotricista Myrtha Chockler, que no curso O Desenvolvimento do bebê: Um Novo Paradigma. O Conceito de Protoinfância (2017), propõe uma outra perspectiva para pensar o corpo na Educação Infantil. Ela diz que precisamos estar atentos para perceber a competência das iniciativas e a potência das crianças como sujeitos desde muito cedo. Ela nos conta, que por meio do movimento e ações, as crianças descobrem a si mesmas e interagem com o mundo (informação verbal). ${ }^{\text {iv }}$

Ainda segundo Chockler (2017), não temos um corpo; somos um corpo e a criança é um corpo (informação verbal). Não existe o não movimento. Mesmo quando estamos aparentemente imóveis, estamos em movimento. Sendo assim, não há nada que aconteça conosco que não se dê através do corpo, pois tudo está em movimento - o sangue, a pele, os músculos etc. O corpo é esse lugar da trama relacional onde vivemos as emoções. Sendo assim, ele é entendido como o espaço de construção simbólica a partir da relação com o outro, com o objeto e seus significados, de acordo com a interação de cada criança e a disponibilidade do adulto. 


\section{Narrativa II:}

Pedro corre pelo pátio. É hora do brincar livre. Entre bambolês, cordas e cones espalhados, vejo algumas crianças escalando as paredes da pequena casinha que fica ali, ao redor das grades que separam as crianças de uma árvore que fica nos olhando lá de fora.

Eu gosto de trazer o céu para os nossos encontros, não só para falar da cor azul, mas para o momento do relaxamento, onde as crianças deitam e olham pra ele. Alguns olhos ficam abertos e outros fechados... Umas crianças costumam falar, outras ficam em silêncio... Às vezes, passa um pássaro. Outras, as nuvens brincam de ser coisas que a imaginação das crianças quer ver.

Mas nesse dia o céu ficou só nos olhando mesmo, porque o Pedro resolveu ser luz. Enquanto todo mundo corria, ele ia pegar folhas secas que vinham voando e pulavam os muros da escola numa tentativa de dizer às crianças que a natureza também podia ser para brincar. Pedro dobrou a camisa para dentro e ali guardou as folhas que pegava. Quando achou que tinha o suficiente, andou com cuidado até um outro canto mais tranquilo, colocou as folhas no chão e começou a juntá-las. Estava tão concentrado que me chamou atenção. Fiquei olhando de longe...

Eu já tinha interrompido demais as criações infantis e tinha aprendido que sempre que eu perguntava alguma coisa, a criança saía de seu mundo e começava a habitar o meu. E ao final, ela não continuava o que estava fazendo. Saía correndo ou se perdia do que seu lado de dentro tentava dizer para fora. Então, dessa vez eu fiquei de longe, mas as outras crianças não. Elas foram chegando, chegando... Umas ficavam olhando, outras ajudavam a colocar uma folha sobre a outra... Até que uma perguntou:

- O que é isso?

Pedro respondeu:

- Estou fazendo uma fogueira.

E logo o fogo imaginário começou a subir e eu via tudo acontecer sem que precisassem de mim. As crianças têm lindas ferramentas internas. Começaram a esticar os bracinhos e fingir que esquentavam as mãos... alguns sopravam... E logo a ideia do Pedro fez uma roda se formar em torno daquela pequena porção de folhas, que tinham se atrevido a pular sobre o concreto com a ajuda do vento. Foi uma cena linda! O gesto infantil tem essa capacidade de transformar, criar, conectar e aconchegar. 
Em liberdade, as crianças vão desenvolvendo sua autonomia e nos contam, com seus gestos espontâneos, sobre o que são, sentem e desejam. Todo educador deveria experimentar esse momento, onde o seu corpo adulto silencia para dar espaço para as crianças acontecerem em paz. Se elas quiserem que você participe, farão um convite claro e direto.

É preciso respeitar a infância e aproveitar a experiência com as crianças, para aprender a perceber se o tempo é de aproximação ou distanciamento. Se o corpo da criança quer o seu, ela vai se aproximar. Se isso não acontecer é porque seu desejo é estar consigo ou com outros pequenos.

A presença do adulto, muitas vezes silenciosa, não deixa de ser afetiva se permite à criança vivenciar o mundo em seus processos de experimentar e criar.

\section{Narrativa III:}

Em uma manhã de céu azul, iluminado pelo sol, no mês de março, decidimos fazer um lanche diferente. Tínhamos como possibilidades o refeitório da escola ou um pátio livre para uma refeição em grupo. A segunda alternativa era a mais interessante, por isso, convidamos o "Grupo da Praça" (crianças entre 3 e 4 anos) para um lanche ao ar livre.

Nos sentamos em volta de uma toalha quadriculada, embaixo de uma das árvores presentes naquele espaço. Tínhamos frutas e suco para saciar nossa fome, enquanto sorrisos e conversas em pequenos grupos alegravam as crianças.

Suzana não queria lanchar e saiu correndo pelo pátio. Seu desejo, naquele momento, era brincar e explorar o espaço sozinha e nós permitimos. Procuramos entender a necessidade de Suzana e ficamos observando-a de longe.

É importante perceber que não permitir essa experiência seria negar a existência dela, desconsiderando-a como sujeito de direitos. "Devemos entender o movimento como a forma natural de expressão do corpo. Um corpo que vive: se move, sente, percebe, muda, imagina, pensa, fala..., exibe o movimento em suas diferentes formas (a pessoas se revela em sua unidade)" (FRANCH e MATRASCUSA, 2016, p. 31). Encontros como esse me constituem como professora, no olhar e escuta sensível e no diálogo corporal com as crianças.

Matheus que não participava das vivências coletivas, não se sentia bem em espaços com muitas crianças e com barulho excessivo. Ele sorriu para os amigos, lanchou, brincou, compartilhou esse momento com todos e abraçou suas professoras. 
Próximo ao final da manhã, após esse encontro potente e regado de afeto ele buscou meu colo como quem procurava sua fortaleza para descansar em segurança, me olhou nos olhos e falou meu nome pela primeira vez, permitindo uma conexão mais profunda entre nós dois. Assim nos conectamos, para juntos vivenciarmos um ano de muitas barreiras, desafios, possibilidades, conquistas, alegrias e aprendizagens. (Registro da professora III, Rio de Janeiro, março de 2019).

Essa narrativa descreve o encontro afetuoso entre professora e criança, que se concretiza pelos enlaces do corpo que sente e se expressa na relação com o outro.

\section{Considerações Finais}

As crianças criam, interpretam e descobrem o mundo por meio das interações. A prática educativa deve levar em conta as relações dos diálogos entre os corpos, respeitando a experiência singular de cada ser.

Somos construídos de muitos outros que vão formando nossos fios ao longo da vida. Por isso, precisamos dar visibilidade aos corpos que pulsam na escola e criar condições para o desenvolvimento pleno, cheio de sentidos e significados, ampliando o repertório e as narrativas do fazer, sentir, viver e aprender, visando o fortalecimento de um desenvolvimento humano positivamente integrado em sua unidade corpo e mente.

Os encontros entre professoras e crianças devem potencializar a ação educativa. Aqui narramos momentos de interação e convivência, onde os vínculos afetivos se mostram importantes não apenas para a interação no espaço escolar, mas principalmente para a constituição do ser humano, criança, que necessita do olhar e escuta atentos dos docentes que a acompanham em seus movimentos de aprender. Escrevemos sobre o corpo como encontro, aquele que precisa estar em relação, para existir.

Este artigo mostra a importância do se aproximar, estar perto no acompanhar, mas ao mesmo tempo, saber manter uma distância que não sufoque o gesto infantil. Um estar docente que permita a criação com o saber adulto, mas que também abre espaço para que a criança possa se desenvolver em paz e liberdade.

É preciso compreender a parte e o todo que forma essa teia. Assim, a aprendizagem se potencializa por meio da brincadeira, da construção do vínculo, da afetividade nas relações e dos encontros potentes a partir de vivências em suas múltiplas linguagens. 
Por acreditarmos que o caminho se constrói com cada criança, lutamos por uma educação que não venha pronta. Por isso, ao invés de finalizarmos com respostas, propomos a reflexão das seguintes perguntas: como você se relaciona com as crianças? Os encontros do seu grupo potencializam ou diminuem os desejos e a alegria?

A aprendizagem não deve andar em círculos. Ela deve acontecer aberta para o desenho de traçados infinitos com grandes e pequenos passos lado a lado.

\section{REFERÊNCIAS}

BATISTA, Maria Isabel; LAPIERRE, Anne; VIEIRA, J. Leopoldo. Psicomotricidade Relacional: a teoria de uma prática. CIAR, 2005.

BUSS-SIMÃO, Márcia. Experiências sensoriais, expressivas, corporais e de movimento na Educação Infantil. In: MORO, Catarina; VIEIRA, Daniele (org.) Leituras em Educação Infantil: contribuições para a formação docente. Curitiba: NEPIE/ UFPR, 2019.

CAMPOS, Gastão. A construção de vínculo, o responsabilizar-se pela saúde da população de uma microrregião, e o encarregar-se de casos singulares. In: Saúde Paideia. São Paulo: Huciec, 2003.

COSTA, Eduardo. (org.) Corpo Transbordante: relatos da prática transpsicomotora educacional e clínica. Rio de Janeiro: Wak Editora, 2017.

ESPINOSA, Benedictus. Espinosa - Os pensadores. São Paulo: Abril Cultural, 1983.

FERRARO, Giusepe. A escola dos sentimentos - Da alfabetização das emoções à educação afetiva. Rio de Janeiro: NEFI, 2018.

FERREIRA, Michelle; GUEDES, Adrianne; LAGE, Lívia. Retratos do Cotidiano: Iluminando "pontos cegos" 2 das Práticas na Educação Infantil. In: MORO, Catarina; VIEIRA, Daniele (org.) Leituras em Educação Infantil: contribuições para a formação docente. Curitiba: NEPIE/ UFPR, 2019.

FOCAULT, Michel. Vigiar e Punir. Petrópolis: Vozes, 1987.

FRANCH, Núria; MASTRASCUSA, Celso. Corpo em movimento, corpo em relação: Psicomotricidade Relacional no ambiente educativo. 1ed. São Paulo: Evangraf, 2016. GALVÃO, Izabel. Henri Wallon: uma concepção dialética do desenvolvimento infantil. Petrópolis, RJ: Vozes, 2011.

PIORSKI, Gandhy. Brinquedos do chão: A natureza, o imaginário e o brincar. São Paulo: Petrópolis, 2016. 
SARMENTO, M. J. As culturas da infância nas encruzilhadas da $\mathbf{2}^{\mathrm{a}}$ modernidade. Braga, Portugal. Universidade do Minho. Centro de Estudos da Criança (mimeo), 2002.

SOARES, Suzana. Vínculo, movimento e autonomia. Omnisciência. São Paulo: 2017.

TIRIBA, Lea. Crianças, Natureza e Educação Infantil. Tese de Doutorado. PUC, Rio de Janeiro, 2005.

TIRIBA, Lea. Crianças da Natureza. Anais Do I Seminário Nacional: Currículo em Movimento - Perspectivas Atuais. Belo Horizonte, novembro de 2010.

TRINDADE, Rafael. Espinosa - Origem e natureza dos afetos. Razão Inadequada. Disponível: https://razaoinadequada.com/2014/07/15/espinosa-origem-e-natureza-dosafetos/ Acesso: 28/07/2020.

WALLON, H. A evolução psicológica da criança. Tradução de Cláudia Berliner. São Paulo: Martins Fontes, 2007.

\footnotetext{
${ }^{i}$ Atua como educadora na Educação Infantil da Escola Oga Mitá e transpsicomotricista na InfanciArte Casa de Brincar. Licenciada em Pedagogia pela UNESA-RJ e com pós-graduação em Educação Infantil pela PUC-Rio. Formação em Transpsicomotricidade Educacional (IFHT/UERJ) e em Arte-Educação (Formae-RJ). É brinquedista (UNESA), artesã e bordadeira. Possui também formação em dança-desenho: Segni-Mossi, realizada em Montevideo-Uruguai. Tem experiência na atuação como transpsicomotricista educacional em creches e escola. Desde 2017 coordena a Colônia de Férias da Escola Oga Mitá. Pesquisadora do Grupo de Estudos e Pesquisa "Infâncias, Tradições Ancestrais e Cultura Ambiental", Gitaka (UNIRIO). Rio de Janeiro-RJ/Brasil. E-mail: lucinhacarpediem@yahoo.com.br ORCID: https://orcid.org/0000-0003-2042-8015

ii Mestranda em Educação pela Universidade Federal do Estado do Rio de Janeiro (UNIRIO), Psicomotricista Educacional, Graduada em Educação Física pela Universidade Federal do Rio de Janeiro (UFRJ). Participante do grupo de estudos GITAKA (Infâncias, tradições ancestrais e cultura ambiental). Petrópolis-RJ/Brasil. mailto:mari2lopez@hotmail.com ORCID: https://orcid.org/0000-0002-9719-4520

iii Possui graduação em Pedagogia pela Universidade Federal do Rio de Janeiro (2017). Especialista em Educação Psicomotora pela Pró-Reitoria de Pós-Graduação, Pesquisa, Extensão e Cultura (Propgpec) do Colégio Pedro II. Cursa mestrado em Educação pela Universidade Federal do Estado do Rio de Janeiro (UNIRIO), participa do grupo de pesquisa GITAKA: Infâncias, Tradições Ancestrais e Cultura Ambiental junto à professora Lea Tiriba. Rio de Janeiro-RJ/Brasil E-mail raiannebernardo95@ gmail.com ORCID: https://orcid.org/0000- 0003

${ }^{\text {iv }}$ Fala da psicomotricista Myrtha Chockler, no curso O Desenvolvimento do bebê: Um Novo Paradigma. O Conceito de Protoinfância em julho de 2017.
}

Revista Interinstitucional Artes de Educar. Rio de Janeiro, V. 7, N. 1 - pág. 132-150 janeiroabril de 2021: "Pedagogias Vitais: Corpo, Desejo e Educação" DOI: 10.12957/riae.2021.54496 